\title{
Suitability Assessment of Lean Kitting Assembly through Fuzzy Based Simulation Model
}

\author{
B. Vijaya Ramnath \\ Research Scholar, \\ Dept. of Production Technology, \\ M.I.T.Campus, Anna University, \\ Chrompet, Chennai-600 044.India
}

\author{
C. Elanchezhian \\ Research Scholar, \\ Dept. of Production Technology, \\ M.I.T.Campus, Anna University, \\ Chrompet, Chennai, India.
}

\author{
Dr. R. Kesavan \\ Asst.Professor, \\ Dept. of Production Technology, \\ M.I.T.Campus, Anna University, \\ Chrompet, Chennai, India.
}

\begin{abstract}
The success of an industry depends on its product's quality, cost and delivery time. So, now a days all manufacturers are trying to implement new manufacturing methods for their production process. In this paper, an attempt has been made to find the suitability of new assembly method known as Lean Kitting assembly for a leading two wheeler manufacturer in India. Lean Kitting means supplying assembly station with kit of components. Even though lot of Multi Criteria Decision Making (MCDM) models like AHP, ANP and PVA are available, a Fuzzy Based Simulation (FBS) model is necessary to assure the suitability by considering important factors and simulate the factors with data given by the experts in those fields. This paper mainly focused on the modeling of a 'Fuzzy Based Simulation' for finding the suitability of the Lean Kitting system by considering the following important factors: Work In Process inventory, Floor space required, operator walking distance.
\end{abstract}

\section{Keywords}

Lean Kitting assembly, Fuzzy Based Simulation (FBS), work in process inventory, floor space required, operator walking distance.

\section{INTRODUCTION}

Lot of works have been done with MCDM models like Performance Value Analysis, Analytical Hierarchy Process, Analytical Network Process and Fuzzy logic. Here various literatures on MCDM are discussed.

Andrea D' Angelo, Massimmo Gastaldi, Nathan Levaldi (1986) have investigated an automated PCB manufacturing plant, to select the statistically significant variables and to determine the relative impact on system performance.

Bozer and McGinnis (1992) define a kit as "a specific collection of components and/or sub assemblies together and combine with other kits to support one or more assembly operations for a given product". They developed a descriptive model which can be used to quantify the trade off in material handling, space requirement and Work In Process between kitting and line stocking for an assembly of stationary fitness cycle.

Brynzor and Johansson (1995) focuses on design of kitting system in terms of location of the order picking activity, work organization, picking method, information systems and equipment. Some of the design aspects and performances from some case studies are discussed like Traveling time and distance, picking information, Design of picking package, picking accuracy and manual picking techniques. In the kitting system, results show that picking efficiency and accuracy can be improved by making better use of the product structure when dividing picking information.

Guiffrida and Nagi (1998) have developed a Mathematical programming approaches include only tangible criteria, and have been extensively used for vendor selection. They include fuzzy programming, utility theory and chance constrained programming, utility theory and interval programming. fuzzy goal programming, interval-programming, mixed integer nonlinear programming, and stochastic integer programming.

Holland (1995) have proposed a integrated fuzzy multiple criteria decision making (MCDM) techniques for solving vendor selection problems, he utilized triangular fuzzy numbers to express the subjective preferences of evaluators with respect to the considered criteria, and also use the criterion gauges to evaluate a well-known high-tech manufacturing company.

Kumar and Vrat (2004) developed a fuzzy goal programming approach to deal with the effect of information uncertainty in the objectives of vendor selection process, and showed how the quota allocation of vendors is varied with uncertainty.

Liu Baoding and Liu Yankui (2002) expressed as In supplier selection decisions, two issues are of particular significance. One is what criteria should be used, and the other, what methods can be used to compare suppliers.

Ghodsypour and O'Brien (1998) proposed an integration of an analytical hierarchy process and linear programming to consider both tangible and intangible factors in choosing the best vendors and placing the optimum order quantities among them such that the total value of purchasing is maximized.

Ravisankar and Verma (2006) developed general framework for vendor-related issues in the context of supply chains, and the status of vendor selection decisions in particular, how to relate uncertainty factors in vendor selection decisions, and the role of suppliers in buyer-supplier relationships in the Indian manufacturing firms.

Zhu (2004) proposed the use of the analytic hierarchy process (AHP) to deal with imprecision in vendor choice. They used the analytical hierarchical process (AHP) to generate weights for the vendor selection decision.

Karthick (2008) has proposed an integrated multi criteria supplier selection process and use of PVA in the actual selection process. He also developed a program in MATLAB to calculate the aggregated performance measure for each supplier. Category analysis is also performed for certain significant criteria to see 
how the alternatives perform with respect to a significant criterion.

Maike Scherrer Rathje, A. Boyle, Deflorin, (2009) have identified the major criteria and conditions that led to either lean success or failure. They found the sources for failure, like the lack of senior management commitment, lack of interest and low acceptability of workers for changes. The sources of successes are employee autonomy to make decisions, information transparency, etc.

Satu Peltola et al. (2002) emphasized the use of Analytical Hierarchy Process (AHP) and integrated Group Support System (GSS) method for improving the business performance in every sector. The utilization of external resources, including a supplier network, has become one of the most critical development areas of business, needing a lot of attention.

Jiann Liang Yang et al. (2008) proposed an integrated fuzzy multiple criteria decision making (MCDM) techniques for vendor selection problems. Jiann utilized triangular fuzzy numbers to express the subjective preferences of evaluators with respect to the considered criteria. In addition, a relationship map is constructed to identify the independence or interdependence of the sub-criteria of a criterion by using interpretive structural modeling (ISM).

Banar, Kose and Ozkan (2006) uses Analytical Network Process (ANP), one of the multi-criteria decision making (MCDM) tools to choose one of the four alternative landfill sites for the city of Eskisehir, Turkey. For this purpose, Super Decision Software has been used and benefit opportunity cost and risk (BOCR0 analysis has been done to apply ANP.

Amir Sanayei (2008) proposed an integrated approach of multiattribute utility theory (MAUT) and linear programming (LP) for rating and choosing the best suppliers and defining the optimum order quantities among selected ones in order to maximize total additive utility. A numerical example is solved to illustrate an application of the proposed method.

Elena Tsiporkova and Veselka Boeva (2006) has introduced a decision model, in the form of a recursive aggregation algorithm, which attempts to imitate a multi-step ranking process of a set of alternatives in a multi-criteria and multi-expert decision making environment

Desheng Wu et al. (2008) considers three types of risk evaluation models within supply chains such as chance constrained programming (CCP), data envelopment analysis (DEA), and multi-objective programming (MOP) models.

From the above literature review it was observed that a fuzzy based simulation model may be developed to find the suitability of lean kitting assembly system for the case situation considered as it involves multiple criteria for the selection process.

A suitable assembly system is expressed by the following equation:

'Suitable assembly system' = f [Work In Process inventory, Floor space required, operator walking distance] (Eq. 1)

Therefore the above equation is optimized with use of fuzzy logic. In recent years, a number and variety of applications of fuzzy logic have increased significantly. The applications range from consumer products such as cameras, two wheelers, washing machines, televisions, cell phones and microwave ovens to industrial process control, medical instrumentation, decisionsupport systems, and portfolio selection. Here the work focuses on identifying the suitability of Lean Kitting assembly by Fuzzy Based Simulation (FBS) model. Therefore, the most important factors like Work In Process inventory, floor space required and operator walking distance are taken into account. Fuzzy Logic Toolbox with MATLAB is a tool for solving problems with fuzzy. The result shows that the selection of Lean Kitting assembly is acceptable and suitable for the case situation considered.

\section{FUZZY INFERENCE SYSTEM}

The fuzzy inference system contains the following major five steps. They are i) Fuzzifier, ii) Rule base, iii) Fuzzy inference engine, iv) Defuzzifier and v) output quantity. The fuzzy inference system is shown in Figure 1.

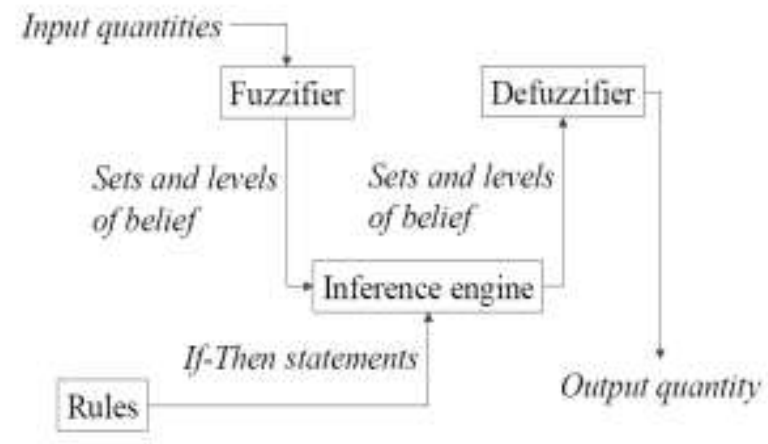

Figure 1

\subsection{Fuzzification for selecting suitable assembly method}

The fuzzification process is performed during run time and consists of assigning membership degrees to Work In Process inventory, Floor Space required, and Operator walking distance. The Figure 2 shows the fuzzification process of a fuzzy logic system with input and output being fuzzified with suitable membership function. Here the inputs are the factors like Work In Process inventory, Floor Space required, and Operator walking distance. The output is the result whose value shows whether to accept, reject or poor for selection of Lean - Kitting assembly as shown in Figure 3. 


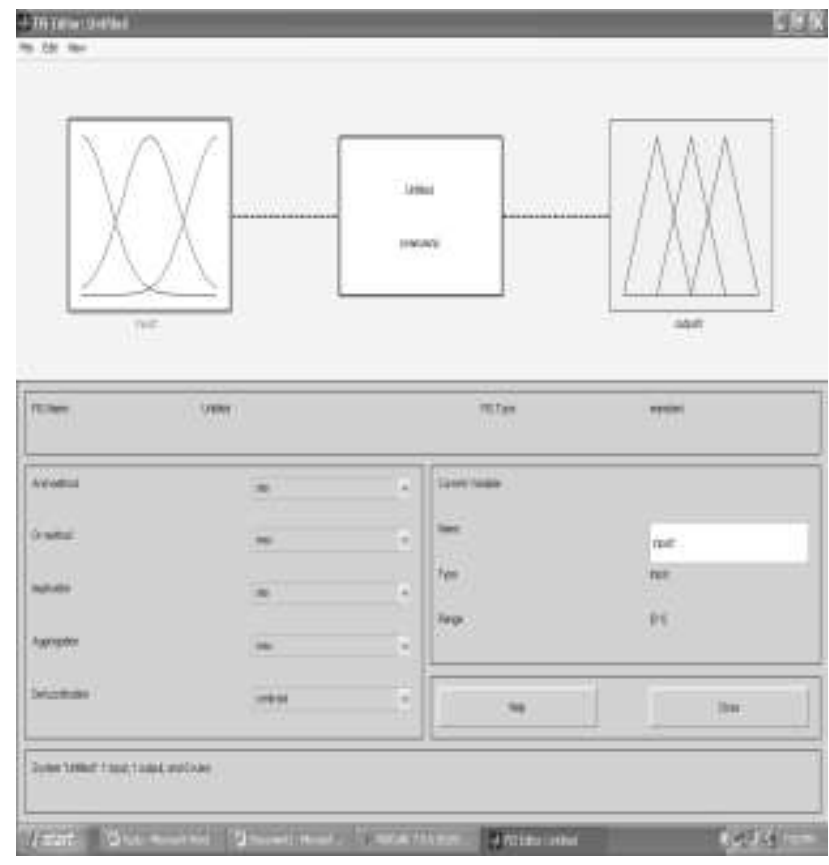

Figure 2

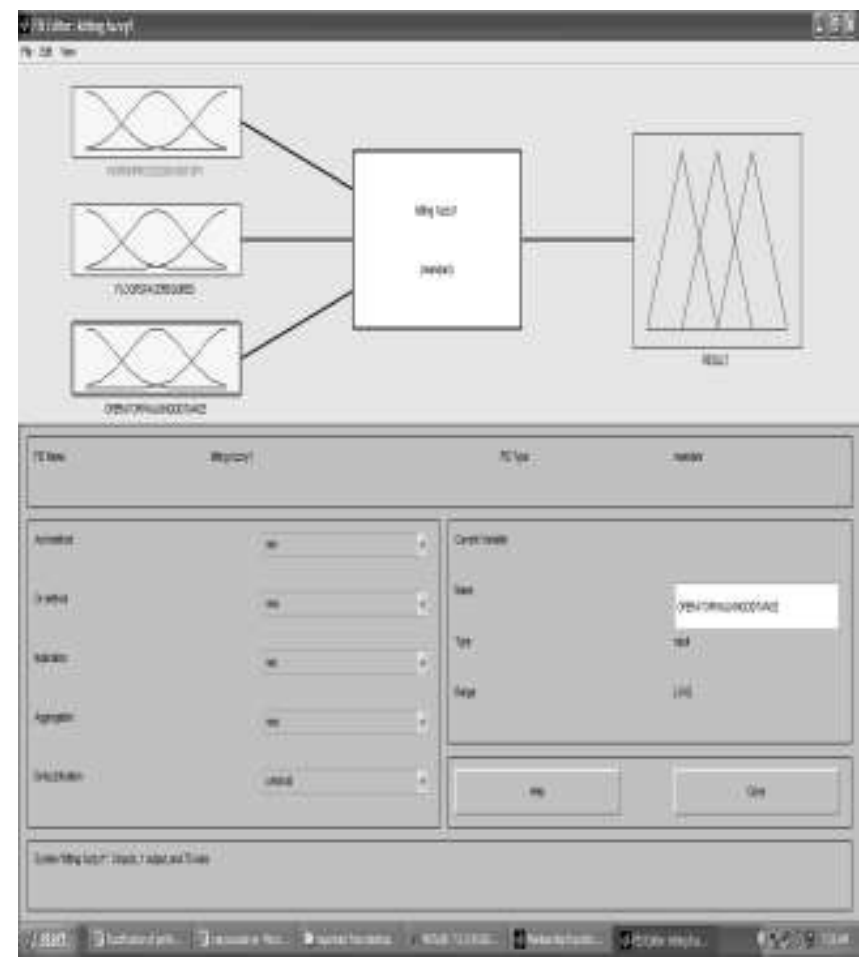

Figure 3

\subsubsection{Work In Progress Inventory(WIP Inventory)}

Work in process inventory is measured by counting the available raw materials and semi finished product in the assembly line. The categories in the measure are very less, less, optimum, more, and very high. If WIP inventory between $10-20 \%$ less or more than the actual WIP, inventory is considered as very less or very high.
Similarly if WIP inventory between $5-15 \%$ less or greater then the actual WIP inventory, is considered as less or more. Optimum WIP inventory has the inventory less or more than 5\% the actual inventory. The transfer function in fuzzy format is shown in Figure 4.

\section{Table 1. Range for WIP Inventory measurement}

\begin{tabular}{|c|c|c|}
\hline Fuzzy & Linguistic Variable & Range \\
\hline 1. & Very less & -20 to 10 \\
\hline 2. & Less & -15 to -5 \\
\hline 3. & Optimum & -5 to 5 \\
\hline 4. & More & 5 to 15 \\
\hline 5. & Very high & 10 to 20 \\
\hline
\end{tabular}

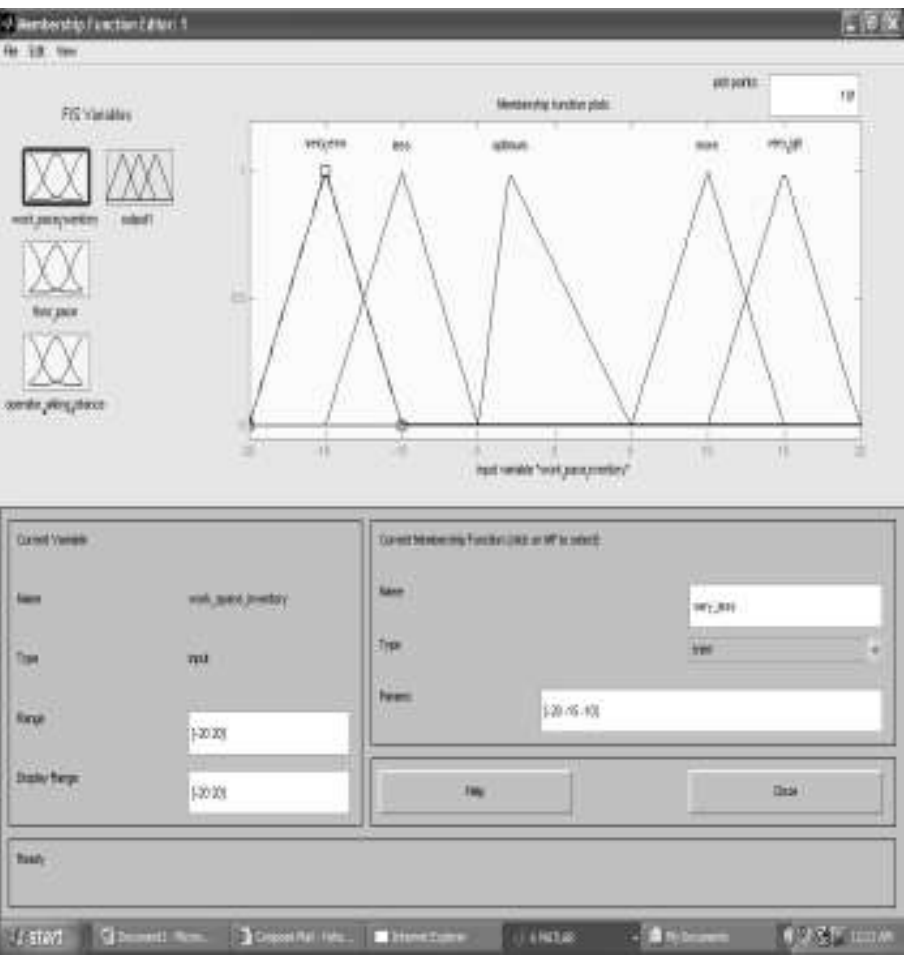

Figure 4

\subsubsection{Floor space required}

Floor space is measured and evaluated based on the space required to place machines and raw materials. The categories in the measure are very less, acceptable less, optimum, acceptable high, very high. If the available floor space is less or more than $6 \%$ of required value then it is considered as very high or very less. If the available floor space is between $3-5 \%$ less or greater then the required value then it is considered as acceptable less or acceptable high. If the available floor space is $2 \%$ less or greater than the required value then it is considered as optimum. The transfer function in fuzzy format is shown in Figure 5. 
Table 2. Range for Floor Space required measurement

\begin{tabular}{|c|c|c|}
\hline Fuzzy & Linguistic Variable & Range \\
\hline 1. & Very less & -6 \\
\hline 2. & Acceptable less & -5 to $-3 \%$ \\
\hline 3. & Optimum & -2 to $2 \%$ \\
\hline 4. & Acceptable high & 3 to $5 \%$ \\
\hline 5. & Very high & $6 \%$ \\
\hline
\end{tabular}

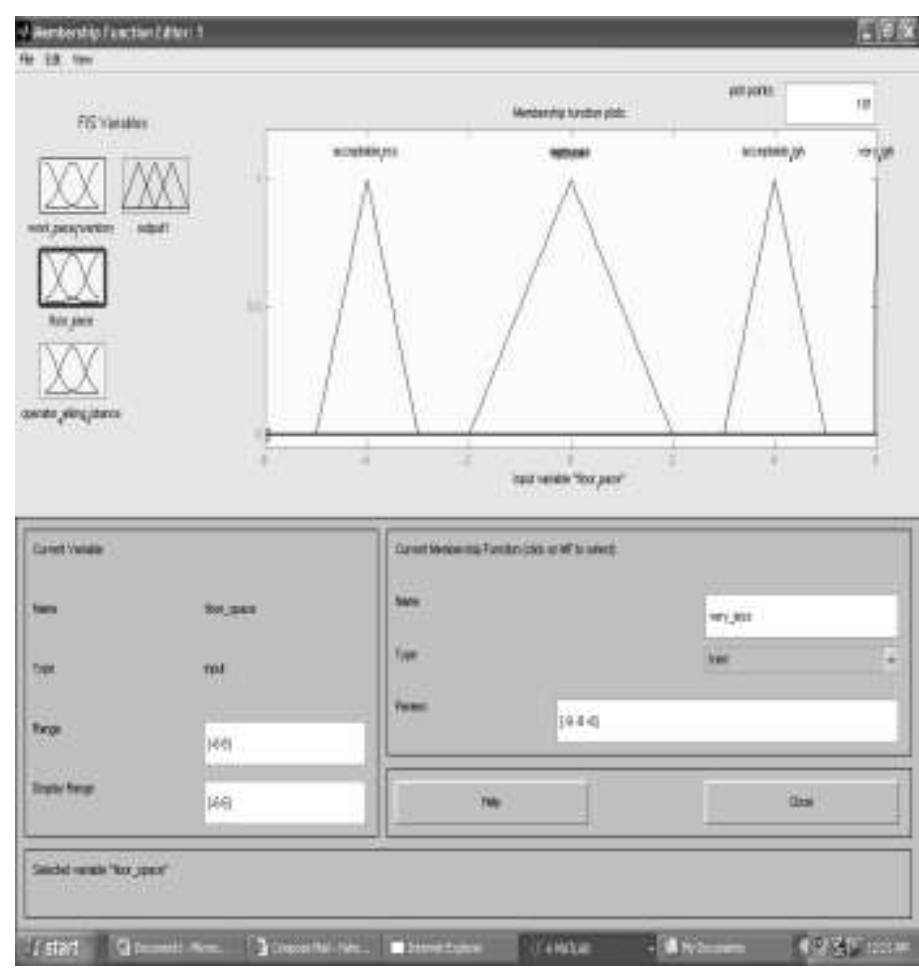

Figure 5

\subsubsection{Operator walking distance}

Walking distance is the distance covered by the operator to perform the required process to finish a operation. If the actual walking distance is less or more than $6 \%$ of required distance, then it is considered as very less or very high. If the actual distance is less or greater than $4-5 \%$ of the required distance, then it is considered as less or high. If the actual walking distance is $3 \%$ less or greater than the required distance, then it is considered as optimum. The transfer function in fuzzy format is shown in Figure 6.

Table 3. Range for Operator walking distance measurement

\begin{tabular}{|c|c|c|}
\hline Fuzzy & Linguistic Variable & Range \\
\hline 1. & Very Less & -6 \\
\hline 2. & Less & -5 to $-3 \%$ \\
\hline 3. & Optimum & -3 to $3 \%$ \\
\hline 4. & High & 4 to $5 \%$ \\
\hline 5. & Very High & $6 \%$ \\
\hline
\end{tabular}

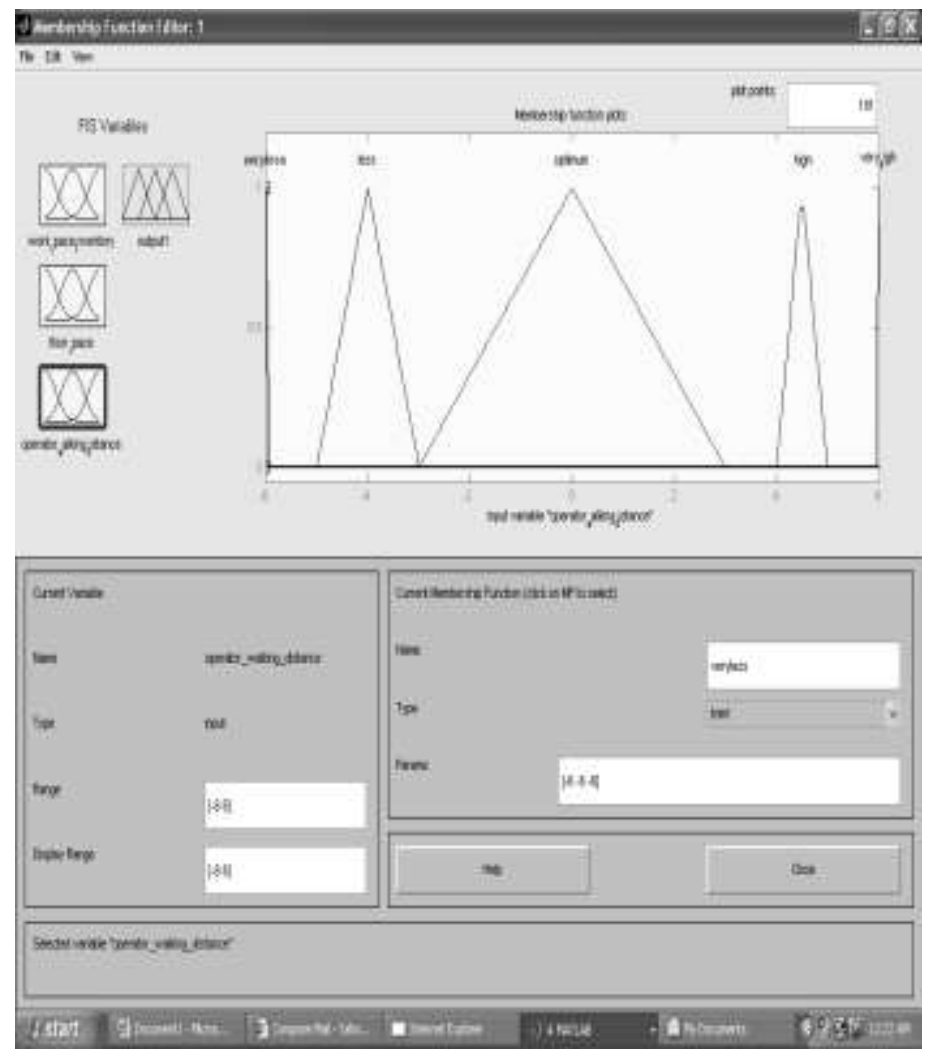

Figure 6

\subsubsection{Result}

The result is to decide whether to select the Lean Kitting assembly or not. The result value lies between 0 to 4 is considered as reject the Lean Kitting assembly, between 4 to 6 is considered as poor and between 6 to 10 is considered as accept the system. The transfer function in fuzzy format is shown in Figure 7.

Table 4. Range for Result-output measurement

\begin{tabular}{|c|c|c|}
\hline Fuzzy & Linguistic Variable & Range \\
\hline 1. & Accept & 6 to 10 \\
\hline 2. & Poor & 3 to 6 \\
\hline 3. & reject & 0 to 3 \\
\hline
\end{tabular}




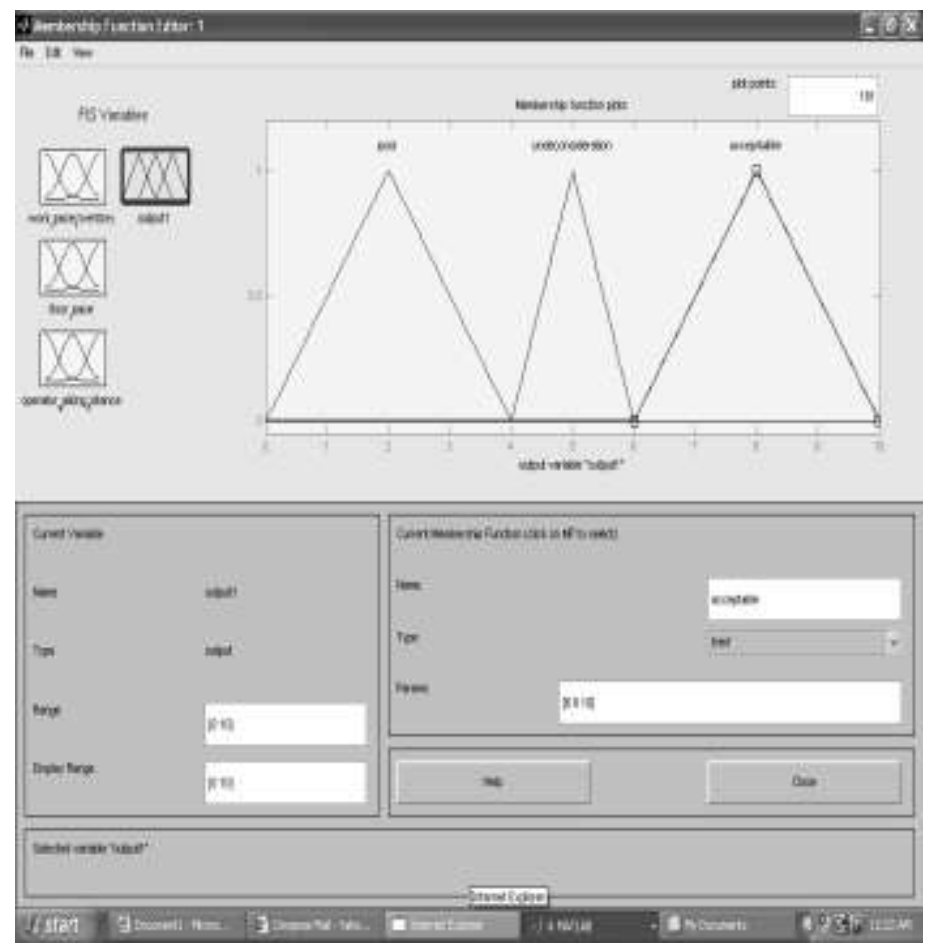

Figure 7

\section{FUZZY EVALUATION RULES (IF- THEN RULES)}

These if-then rule statements are used to formulate the conditional statements that comprise fuzzy logic. A single fuzzy if-then rule assumes the form "if $\mathrm{x}$ is $\mathrm{A}$ then $\mathrm{y}$ is B" where A and B are linguistic values defined by fuzzy sets. The if-part of the rule " $x$ is A" is called the premise, while the then-part of the rule "y is B" is called the conclusion. There are 75 rules following the format 'if (condition a) and (condition b) and (condition c) then (result c)' corresponding to the combination of input conditions is shown in Figure 8. For example, 'if work in process is less' and 'floor space required is acceptable less ' and 'operator walking distance is less' then the result is 'the system is acceptable'. The rules are formed with the expert knowledge, feedback and guidance given by experts in the manufacturing industries and are further refined with experienced persons in the field of operation, production management and are further refined, following real life application and appraisal which will either confirm them or require them to be modified. The following Tables 5, 6, and 7 shows the formation of fuzzy rules.

Table 5. Fuzzy rule for Work In Process (WIP) inventory 'less'

\begin{tabular}{|l|l|l|l|l|l|}
\hline \multicolumn{1}{|c|}{$\begin{array}{l}\text { Operator } \\
\text { walking } \\
\text { distance }\end{array}$} & Very less & less & optimum & high & $\begin{array}{l}\text { Very } \\
\text { high }\end{array}$ \\
$\begin{array}{l}\text { Floor } \\
\text { space } \\
\text { required }\end{array}$ & & & & & \\
\hline Very less & Accept & Accept & Accept & Poor & Reject \\
\hline Acceptable less & Accept & Accept & Poor & Poor & Reject \\
\hline Optimum & Accept & Accept & Poor & Reject & Reject \\
\hline
\end{tabular}

\begin{tabular}{|l|c|c|c|c|c|}
\hline Acceptable high & Poor & Poor & Poor & Reject & Reject \\
\hline Very high & Poor & Reject & Reject & Reject & Reject \\
\hline
\end{tabular}

Table 6. Fuzzy rule for Work In Process (WIP) inventory 'optimum'

\begin{tabular}{|l|c|c|c|c|c|}
\hline $\begin{array}{c}\text { Operator } \\
\text { walking } \\
\text { distance } \\
\text { Floor } \\
\text { space } \\
\text { required }\end{array}$ & Very less & less & Optimum & high & $\begin{array}{c}\text { Very } \\
\text { high }\end{array}$ \\
\hline Very less & Accept & Accept & Poor & Poor & Reject \\
\hline Acceptable less & Accept & Accept & Poor & Poor & Reject \\
\hline Optimum & Accept & Poor & Poor & Reject & Reject \\
\hline Acceptable high & Poor & Poor & Reject & Reject & Reject \\
\hline Very high & Reject & Reject & Reject & Reject & Reject \\
\hline
\end{tabular}

Table 7. Fuzzy rule for Work In Process (WIP) inventory 'more'

\begin{tabular}{|l|c|c|c|c|c|}
\hline $\begin{array}{c}\text { Operator } \\
\text { walking } \\
\text { distance } \\
\begin{array}{l}\text { Floor space } \\
\text { required }\end{array}\end{array}$ & $\begin{array}{c}\text { Very } \\
\text { less }\end{array}$ & less & optimum & high & $\begin{array}{c}\text { Very } \\
\text { high }\end{array}$ \\
\hline Very less & Poor & Poor & Reject & Reject & Reject \\
\hline Acceptable less & Poor & Reject & Reject & Reject & Reject \\
\hline Optimum & Reject & Reject & Reject & Reject & Reject \\
\hline Acceptable high & Reject & Reject & Reject & Reject & Reject \\
\hline Very high & Reject & Reject & Reject & Reject & Reject \\
\hline
\end{tabular}

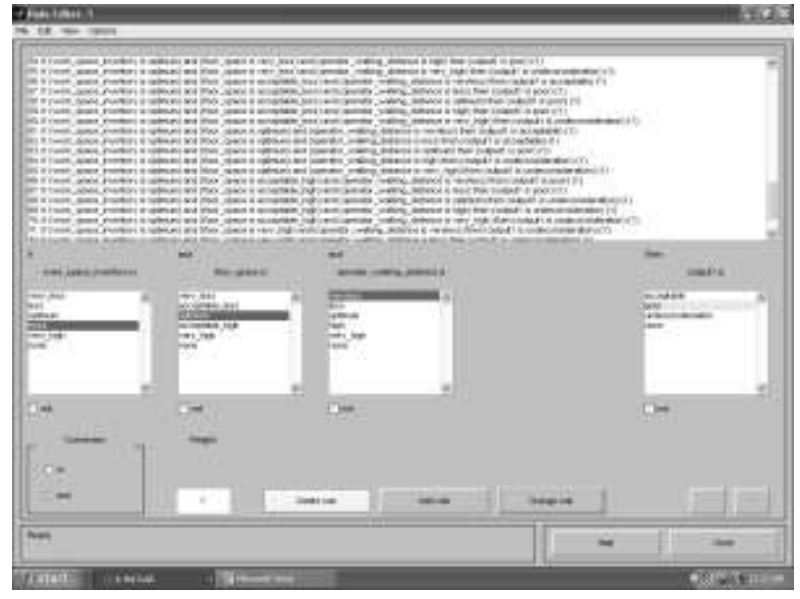

Figure 8

\section{Fuzzy Solution Results}

A continuum of fuzzy solutions for equation (1) is presented in Figure 9 using the fuzzy tool box of MATLAB. The three inputs can be set within the upper and lower specification limits and the output response is calculated as a score that can be translated into linguistic terms. In this instance the order output of 6.79 indicates "Accept" linguistically from Table 4. 


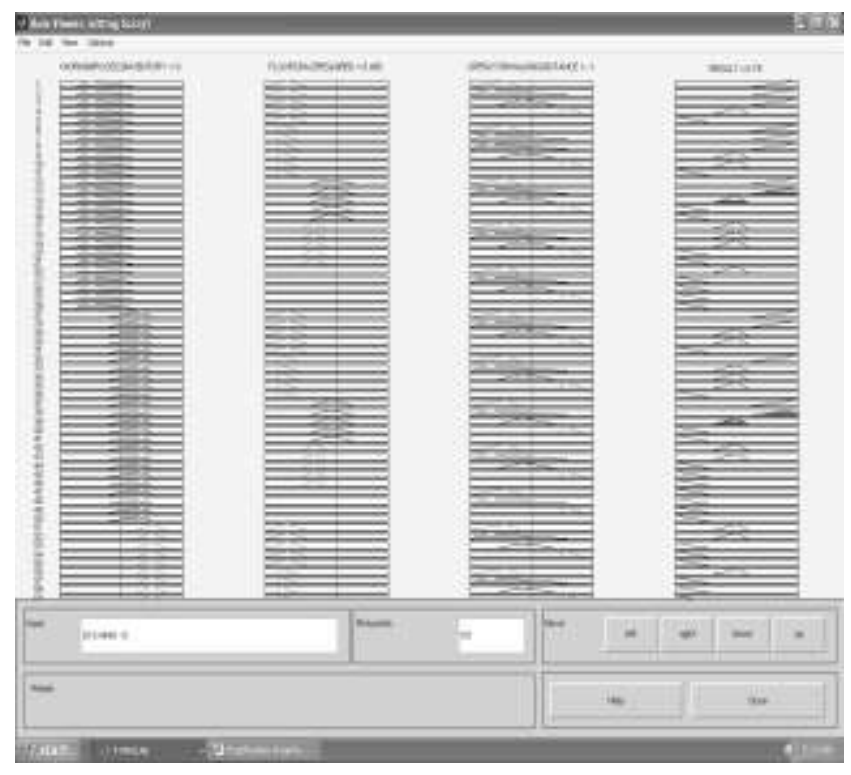

Figure 9

\section{CONCLUSION}

This paper introduced a new model known as 'Fuzzy Based Simulation' (FBS) for finding suitability of Lean Kitting assembly for a assembly line of a leading two wheeler manufacturer. The model considered the important factors like Work In Process inventory, Floor space required, and operator walking distance. This has been seen that the value of result is above 6 (6.79). As per the Fuzzy range for result, the Lean Kitting assembly is suitable and acceptable for the case situation considered in this paper.

\section{REFERENCES}

[1] Angelo D., Gastaldi. M., and Levaldi .N. 1986, Dynamic analysis of the performance of a flexible manufacturing system: a real case application. CIM System, 9, 101-110.

[2] Agarwal.A., Shankar.R., and H.K. Tiwari, 2006, Modeling the Metrics of lean, agile and leagile supply chain: An ANPbased approach. European Journal of Operational Research, 173, 221-225.

[3] Farnaz Akhavi, Caroline Hayes, 2003, A comparison of two multi-criteria decision making Techniques. IEEE.

[4] G.Askin , B.Goldberg, 2003, Design and Analysis of Lean Production Systems, John Wiley \& Sons (Asia) Pvt. Ltd., Singapore.

[5] A. Abdulmaleh, Jayant Rajagopal, 2006, Analyzing the benefits of lean Manufacturing and value stream mapping in a simulation : A process sector case study .Int.Jr. Production Economics.

[6] Banar M, Kose B.M. and Ozkan A. 2006, Choosing a municipal landfill site by Analytical Network Process. Article of Environ Geol, 52, 741-751.
[7] Bragila M. and Petroni A. 2000, A quality assurance oriented methodology for handling trade-offs in supplier selection. International journal of Physical Distribution \& Logistics Management, 30, 96-111.

[8] Bozer.A. and McGinnis.F. 1992, Kitting Vs Line stocking: A conceptual framework and a descriptive model. Int.Jr.of Production Economics, 28, 1-19.

[9] H. Brynzor.H. and Johansson.M.I. 1995, Design and performance of kitting and order picking system. Int.Jr. Production Economics, 4, 115- 125.

[10] Gencer .C. and Gurpinar .D. 2007, Analytical Network Process in supplier selection: A case study in an electronic firm. Applied Mathematical Modelling, 31, 2475-2486.

[11] Lin. C., Chiu.H. and Chu.P. 2006, Agility index in the supply chain. International Journal of Production Economics, 100, 285-299.

[12] Chopra S. and Meindle P. 2001, Supply Chain Management Strategy, Planning and Operation. Prentice Hall Inc., Upper Saddle River, 1-24.

[13] Degraeve Z., Labro E. and Roodhooft F. 2000, An evaluation of vendor selection models from a total cost of ownership perspective. European Journal Of Operational Research, $125,34-58$

[14] Wu .D. and Olson. L. 2008, Supply chain risk, simulation, and vendor selection. International Journal of Production Economics, 114, 646-655.

[15] Dickson G.W. 1996, An analysis of vendor selection systems and decisions. Journal of Purchasing, 2, 5-17.

[16] Celebi.D. and Bayraktar. D. 2008, An integrated neural network and data envelopment analysis for supplier evaluation under incomplete information. Expert Systems with Applications, 35, 1698-1710.

[17] Tsiporkova.E. and Veselka Boeva.V. 2006, Multi-step ranking of alternatives in a multi-criteria and multi-expert decision making environment. International Journal of Information Sciences, 176, 2673-2697.

[18] Roodhooft.F. and Koning.J. 1996, Vendor selection and evaluation - An activity based costing approach. European Journal of Operational Research, 96, 97-102.

[19] Shih.H., Shyur.H., and Lee .S. 2006, An extension of TOPSIS for group decision making. Mathematical and Computer Modelling, 45, 801-813.

[20] Yang.J., Chiu.H., Tzeng.G. and Yeh. R. 2008, Vendor selection by integrated fuzzy MCDM techniques with independent and interdependent relationships. International Journal of Information Sciences, 178, 623-642.

[21] Kasilingam R.G., and Lee C P. 1996, Selection of vendors-A mixed-integer programming approach. Computers \& Industrial Engineering, 31, 120-197

[22] Kumar M., and Vrat P. 2004, A fuzzy goal programming approach for vendor selection problem in a supply chain. Computer \& Industrial Engineering, 46, 69-85. 
[23] Kannan, V., and Tan, K. 2002, Supplier selection and assessment: Their impact on business performance. The Journal of Supply Chain Management, 38, 4-19.

[24] Tamaki.K., and Nof. Y. 1991, Design method of robot kitting system for flexible assembly. Robotics and autonomous systems, $8,255-273$.

[25] Baoding .L. and Yankui. L. 2002, Expected value of fuzzy variable and fuzzy expected value model. IEEE Transactions on Fuzzy Systems, 10, 445-450.

[26] Xiang. L. and Baoding. L. 2006, A sufficient and necessary condition for credibility measures. International Journal of Uncertainty, Fuzziness \& Knowledge-Based Systems, 14, 527-535.

[27] Medbo. L. 2003, Assembly work execution and materials kit functionality in parallel flow assembly systems. Int. Jr. of Industrial Ergonomics, 31, 263 - 281.

[28] Kojima.M., Nakashima.K., and Ohno.K. Performance evaluation of SCM in JIT environment. International Journal of Production Economics, 115, 439-443.
[29] Taghi. M., and Mirheydari. D. 2008, A new framework for evaluation and prioritization of supplier's using a Hierarchy Fuzzy TOPSIS. Proceedings of world academy of science, 31, 1-18.

[30] Houshmand. M., and Jamshidnezhad. B. 2006, An Extended Model of design process of lean production systems by means of process variables, Robotics and computer Integrated Manufacturing, 22, 1-16.

[31] McCauley-Bell. P. 1999, Intelligent agent characterization and uncertainty management with fuzzy set theory: A tool to support early supplier integration. Journal of Intelligent Manufacturing, 10, 135-147.

[32] Sarkis. J. and Talluri. S. 2001, A model for strategic supplier selection. Proceedings of the third worldwide research symposium on purchasing and supply chain management, Canada, 14, 527-535.

[33] Saaty. L. 1990, How to make a decision - The Analytic Hierarchy Process. European Journal of Operational Research, 48, 9-26. 